УДК 332.142.2(518)

https://doi.org/10.24866/1813-3274/2020-3/126-136

С. К. Песцов ${ }^{1}$, Центр глобальных и региональных исследований ИИАЭ ДВО РАН, г. Владивосток, Россия

E-mail: skpfox@yandex.ru

\title{
ТРУДНАЯ ПЕРИФЕРИЯ: СТРАТЕГИЯ И РЕЗУЛЬТАТЫ ОЖИВЛЕНИЯ «РЖАВОГО ПОЯСА» КИТАЯ
}

Аннотация. Оживление Северо-Востока Китая - его старой промышленной базы, превратившейся за годы открытости и реформ в отстающую периферию, является одной из наиболее важных и, одновременно, сложных задач в рамках государственной политики управления региональным развитием. Попытки системного решения этой задачи руководством страны начали предприниматься с начала 2000-х годов. Нельзя утверждать, что инициативы, связанные с усилиями по преодолению периферийности Северо-Востока, за прошедшие годы оказались безрезультатными. В то же время говорить о радикальном переломе негативных тенденций в развитии этого региона довольно затруднительно. Очевидным подтверждением того, что цель «оживления» Северо-Востока всё ещё далеко не достигнута, могут служить все новые инициативы в этом направлении. Нынешняя администрация во главе с президентом Си Цзиньпином, подтверждая сохраняющуюся актуальность проблемы оживления северо-восточного региона, в августе 2014 г. и апреле 2016 г. анонсировала обновление планов решения этой задачи. В данной статье рассматриваются общие подходы и промежуточные итоги государственной политики оживления Северо-Восточного региона КНР, позволяющие сделать некоторые выводы относительно её сильных сторон и недостатков. Предпринятый анализ подтверждает актуальность, как минимум, нескольких важных выводов. Во-первых, достигнутые позитивные изменения в развитии экономики и социальной сферы региона подтверждают значимость согласованной и всесторонней стратегии для управления региональным развитием. Во-вторых, важным обстоятельством, огра-

\footnotetext{
${ }^{1}$ Сергей Константинович Песцов, доктор политических наук, главный научный сотрудник Центра глобальных и региональных исследований Института истории, археологии и этнографии Дальневосточного отделения Российской Академии Наук, г. Владивосток, Россия.

Для циитирования: Песцов С. К. Трудная периферия: стратегия и результаты оживления «ржавого пояса» Китая // Азиатско-Тихоокеанский регион: экономика, политика, право. 2020. № 3. С. 126-136. https://doi.org/10.24866/1813-3274/2020-3/126-136.

* Статья подготовлена в рамках гранта РФФИ № 20-514-93004 «Управление развитием сопредельных территорий России и Китая в начале XXI века: национальные практики как основа теоретической рефлексии».
}

(C) Песцов С. К., 2020 
ничивающим эффективность предпринимаемых усилий, стало долго сохранявшееся упрощённое представление о возрождении старой промышленной базы. Оно сводило эту задачу к проблеме промышленных технологий без учёта важности системной реформы и институциональных инноваций. И, в-третьих, подход, опирающийся преимущественно на согласованные правительственные усилия сверху вниз, вовсе не является гарантией успеха. Таким образом, опыт прошедших лет ясно показывает, что успешное решение задачи оживления китайского «ржавого пояса» возможно только в рамках целостного регионального проекта, объединяющего цели экономического роста, социального прогресса и улучшения экологии, равно как и усилия множества акторов на национальном и локальном уровнях.

Ключевые слова: КНР, Северо-Восток Китая, «ржавый пояс», старая промышленная база, периферия, ресурсная зависимость, региональная экономика, управление региональным развитием, государственная стратегия, структурные реформы, технологические инновации, экономический рост.

Sergey K. Pestsov ${ }^{1}$, Center for Global and Regional Studies, IIAE FEB RAS, Vladivostok, Russia

E-mail: skpfox@yandex.ru

\section{DIFFICULT PERIPHERALS: STRATEGY AND RESULTS OF REVITALIZING THE "RUST BELT" OF CHINA"}

Abstract. Revitalization of the Northeast China's old industrial base, which has turned into a lagging periphery over the years of openness and reform, is one of the most important and, at the same time, most difficult tasks in the framework of the state policy of managing regional development. Attempts to systematically solve this problem by the country's leadership began in the early 2000s. It cannot be argued that over the past years, initiatives related to efforts to overcome the periphery of the Northeast have been unsuccessful. At the same time, it is rather difficult to talk about a radical turn in negative trends in the development of this region. Several new initiatives in this direction can serve as clear confirmation that the goal of revitalizing the North-East is still far from being achieved. The current administration, led by President Xi Jinping, confirming the con-

\footnotetext{
${ }^{1}$ Sergey K. Pestsov, Doctor of Political Sciences, Chief Researcher, Center for Global and Regional Studies, Institute of History, Archeology and Ethnography, Far Eastern Branch of the Russian Academy of Sciences, Vladivostok, Russia.

For citing: Pestsov S. K. Difficult peripherals: strategy and results of revitalizing the "rust belt" of China // Pacific RIM: Economics, Ppolitics, Law. 2020. No. 3. P. 126-136. https://doi.org/10.24866/18133274/2020-3/126-136.

* The article was prepared within the framework of the RFBR grant No. 20-514-93004 "Management of the development of adjacent territories of Russia and China at the beginning of the XXI century: national practices as the basis of theoretical reflection".
} 
tinuing urgency of the problem of revitalizing the northeastern region, in August 2014 and April 2016 announced an update of plans to address this problem. This article examines the general approaches and intermediate results of the state policy of revitalizing the northeastern region, allowing drawing some conclusions regarding its strengths and weaknesses. The analysis confirms the relevance of at least several important conclusions. First, the positive changes achieved in the development of the economy and social sphere of the region confirm the importance of a coordinated and comprehensive strategy for managing regional development. Secondly, an important factor limiting the effectiveness of the efforts being made is the long-held simplistic view of the revival of the old industrial base. It reduced this task to the problem of industrial technology without considering the importance of systemic reform and institutional innovation. And third, a topdown approach, even one that relies heavily on concerted government efforts, is by no means a guarantee of success. Thus, the experience of past years clearly shows that a successful solution to the task of revitalizing the Chinese «rust belt» is possible only within the framework of a holistic regional project that combines economic growth, social progress and environmental improvement, as well as the efforts of many actors at the national and local levels.

Key words: PRC, Northeast China, old industrial base, "rust belt", periphery, resource dependence, regional economy, regional development management, government strategy, structural reforms, technological innovation, economic growth.

Управление региональным развитием, учитывая размеры и географию Китая, а также роль регионов в содействии экономическому развитию страны, традиционно выступает одним из ключевых компонентов общегосударственной политики развития. Одним из наиболее важных и достаточно специфическим объектом приложения усилий традиционно выступает регион Северо-Востока, включающий провинции Лянин, Цзилинь и Хэйлунцзян, а также восточные части автономных районов Внутренней Монголии. Благодаря богатству природных ресурсов, уникальной истории развития и геополитическим отношениям с СССР, этот регион в 1950-1960-е годы возник в качестве первого промышленно развитого района и крупнейшей промышленной базы Китая. Основатель КНР Мао Цзэдун называл Северо-Восток «старшим сыном» страны, на плечах которого, согласно китайской традиции, покоится будущее семьи [4]. Однако за годы реформ положение региона существенно ухудшилось, а сам он превратился в проблемную периферию, для обозначения которой всё чаще используется термин «ржавый пояс». Первоначально это понятие с 1980 г. стало употребляться в качестве неофициального названия для промышленного региона США, вступившего в полосу глубокого и затяжного экономического кризиса, сопровождавшегося деиндустриализацией, упадком городов и депопуляцией. Ныне это 
понятие стало общеупотребительным для определения депрессивных территорий в разных странах, включая и Северо-Восток Китая [6; 10].

\section{Стратегия оживления Северо-Востока: цели и средства}

Задача возрождения Северо-Востока Китая, превратившегося в «ржавый пояс» страны, была сформулирована центральным правительством в начале 2000-х годов в качестве отдельного направления общей политики регионального развития [7]. Специальная региональная политика реформирования старой промышленной база Китая впервые была анонсирована в документе «О реализации стратегии возрождения северо-восточной старой промышленной базы и других старых промышленных баз», обнародованном ЦК КПК и Государственным советом Китая 5 октября 2003 г. Вслед за этим Национальная комиссия по развитию и реформам КНР представила первый список 100 возрождаемых объектов, финансируемых за счёт займов казначейских облигаций. Государственным советом Китая были также учреждены руководящая группа и постоянный офис (Управление Государственного совета по возрождению старой промышленной базы Северо-Востока и других районов (State Council Office for Revitalizing Northeast Old Industrial Base and Other Areas - SCORNOIBOA), призванные координировать реализацию политики [9]. Центральным правительством были определены четыре основные задачи активизации северо-восточного промышленного «ржавого пояса», включая усилия по реструктуризации государственных предприятий (state-owned enterprise - SOE), продвижению частного сектора, оптимизации структуры промышленности и привлечению большего объёма внутренних и зарубежных инвестиций [8]. Правительства провинций Ляонин, Цзилинь и Хэйлунцзян, в свою очередь, начали разработку собственных планов, конкретизирующих программные цели [3].

Углубление реформы государственной системы управления активами и государственными предприятиями, содействующее расширению смешанной собственности и частному сектору экономики, рассматривалось как средство повышения экономической жизнеспособности региона. Оптимизация существующего промышленного комплекса и модернизация его технологий выступали основным средством оживления некогда важных промышленных баз. Северо-Восток должен был продолжать развивать те отрасли, которые в наибольшей степени адаптированы к условиям местных отраслевых комплексов, и одновременно уделять внимание развитию современного сельского хозяйства с целью укрепления позиций в качестве основного производителя и поставщика зерна. Регион нацеливался на расширение открытия своей экономики для других частей страны и остального мира. Местным правительствам рекомендовалось повышать занятость и расширять охват системы социального обеспечения. Крайне важным также являлось решение задач изменения режима экономического роста, предотвращения нерациональных инвестиций и дублирования строительных проектов с использованием низкоуровневых технологий [13]. 
Одновременно Государственным советом была запущена пилотная программа по реформированию налоговой системы в регионе, чтобы стимулировать капиталовложения и техническое перевооружение. Компании в ряде отраслей, таких как машиностроение, нефтехимия, судоходство и транспортные средства, освобождались от уплаты НДС при покупке оборудования и техники с датой 1 июля 2004 г. В марте 2004 г. Государственный совет КНР объявил, что провинции Цзилинь и Хэйлунцзян должны стать двумя единственными экспериментальными районами для отмены сельскохозяйственных налогов [2, р. 8-9]. Инвестиции преимущественно направлялись в программы по корректировке структуры промышленности, преобразованию старых государственных предприятий и осуществлению высокотехнологичных индустриальных проектов.

Региону предлагалось осуществить корректировку структуры собственности, чтобы сократить государственный и расширить негосударственный сектор. Эта стратегия, названная стимулированием реформы существующего масштаба экономики (yi zengliang cu cunliang de gaige zhanlüe), продемонстрировавшая эффективность в прибрежных районах на юго-востоке Китая, теперь должна была помочь оживлению северо-востока. Предполагалось, что развитие негосударственного сектора в регионе не только создаст новые возможности трудоустройства для увольняемых с госпредприятий работников, но и подтолкнёт последние к повышению эффективности и конкурентоспособности благодаря сокращению избыточного числа занятых [2, p. 9]. В соответствии с политическими документами правительства 2003 г., ряд старых промышленных городов на Северо-Востоке Китая были выбраны в качестве пилотных для снятия с ключевых крупных предприятий социальных функций с целью постепенного освобождения их от социального обременения. Социальные расходы предполагалось компенсировать финансами из центрального бюджета. Одновременно планировалось решить вопрос коллективных предприятий, управляемых SOE [5, p. 106].

Для организаций социального обеспечения в трёх северо-восточных провинциях (Ляонин, Цзилинь и Хэйлунцзян) в таких сферах, как базовое пенсионное и медицинское страхование, выделялись дополнительные средства из центрального бюджета. Финансовые ресурсы, предоставленные трём провинциям, составили в 2003-2005 гг. 66,16 млрд юаней, включая 36,93 млрд юаней на базовые пенсионные страховые взносы для работников, 11,94 млрд юаней на пособия на проживание и пособия по безработице для уволенных работников государственных предприятий, 6,71 млрд юаней в качестве суточных для жителей города и 10,58 млрд юаней в качестве средств на иные пилотные проекты по реформе социального обеспечения [5, p. 106-107].

Руководство трёх северо-восточных провинций также представило собственные программы экономических и социальных реформ [11, p. 234-235]. Провинция Ляонин в качестве приоритета объявило структурную перестройку, предполагаю- 
щую укрепление ключевых предприятий с целью превращения провинции в национального и международного производителя оборудования и важного поставщика сырья. Эту задачу предполагалось решить к 2010 г. путём консолидации трёх основных отраслей: нефтехимии, металлургии и производства оборудования. Другие меры включали содействие экономическому развитию уездов для стимулирования экономического развития сельских районов; ускорение развития современной сферы услуг и повышение её качества; поощрение создания новых отраслей промышленности и лёгкой промышленности, а также содействие применению информационных технологий в традиционной промышленности. Собственный комплексный план был представлен провинцией Цзилинь [2]. Осуществляя модернизацию и максимизацию своей промышленности, провинция планировала развивать современное сельское хозяйство и сферу услуг. Для исправления дисбаланса между тяжёлой и лёгкой промышленностью провинция намеревалась стимулировать развитие переработки сельскохозяйственной продукции и производство фармацевтических препаратов [2, p. 11]. Провинция Хэйлунцзян акцентировала внимание на мерах по реорганизации и обновлению государственных предприятий, управляемых местными органами власти, консолидации системы социального обеспечения и ускоренного развития новых отраслей промышленности в городах с истощёнными ресурсами. Основные задачи, которые ставила перед собой провинция, включали удержание уровня безработицы в городе в пределах $5 \%$, ограничение тенденции к ухудшению экологической обстановки и ежегодное увеличение стоимости промышленной продукции более чем на 10\% или увеличение ВВП более чем на $9 \%$. Соответственно, к 2008 году ВВП провинции должно было удвоиться. В качестве приоритета ею были выбраны пять основных отраслей: производство оборудования, нефтехимия, энергетика, производство экологически чистых и специальных продуктов питания, а также фармацевтика [2, p. 11-13].

\section{Стратегия оживления Северо-Востока: промежуточные итоги}

Тем не менее, за годы, прошедшие со времени начала реформ, констатируют специалисты в самом Китае и за его пределами, задача оживления Северо-Востока по-прежнему далека от своего решения. «Регион всё ещё экономически борется с теми же проблемами, с которыми он сталкивался при запуске плана... Последовательные центральные администрации не смогли осознать важность институциональной и управленческой реформы в регионе, сосредоточившись вместо этого на стимулирующей политике, которая преуспела только в сохранении структурных проблем» [3]. Так, чрезвычайно медленными темпами продвигается реформа SOE. Хотя объём промышленного производства госпредприятий в процентном отношении к общему объёму производства с 74\% в 1998 г. снизился до 37\% в 2011 г., однако заметного повышения производительности среди они не продемонстрировали. 
Соотношение потерь к активам в государственных предприятиях региона выросло с примерно $3 \%$ в начале 2000-х годов до более $10 \%$ в последние годы [3]. Серьёзным недостатком, снижающим эффективность усилий, остается неадекватная промышленная политика. Фактическая поддержка региона в области реформы промышленной политики оказалась гораздо слабее той, которая ожидалась. В настоящее время промышленность на Северо-Востоке по-прежнему ещё остается на нижнем уровне цепочки создания стоимости. Хотя за последнее десятилетие производство в значительной степени заменило добычу полезных ископаемых, но строительство и производство электроэнергии, выпуск вторичного сектора по-прежнему возглавляется такими отраслями, как переработка нефти, производство цветных металлов и пищевая промышленность.

Как и прежде, Северо-Восток испытывает гнёт «ресурсного проклятия». Сельскохозяйственные угодья, нефть, древесина и металлы сыграли важную роль в общем развитии Китая. Однако они же сделали его более уязвимым в условиях централизованного планирования и растущих потребностей в ресурсах других регионов. Несмотря на многочисленные заявления, фискальные трансферты северовостоку со стороны центрального правительства в течение последующих десятилетий оставались почти неизменными. Хотя инвестиции в регион из бюджета центрального правительства возросли после объявления в 2003 г. плана оживления, вскоре они вернулись к прежним уровням. Больше того, эти средства часто помогали госпредприятиям списывать их долги, но не мотивировали какие-либо реальные структурные реформы для устранения плохого управления и неэффективности производства [4]. В значительной степени неизменно проблемной остаётся и деловая среда. Бюрократическая волокита и доминирование SOE всё ещё создают серьёзные препятствия для привлечения частных инвестиций из внешних источников, при этом успех в бизнесе основывается больше на выстраивании отношений, нежели на обеспечении производительности. Это выступает тормозом развития местной деловой культуры, поскольку молодёжь северо-востока зачастую предпочитает мигрировать из региона. Ситуация усугубляется тем, что заработная плата, выплачиваемая государственным служащим, которая является одной из самых низких в стране из-за избытка рабочей силы, побуждает чиновников к поиску ренты.

\section{Заключение}

Очевидным подтверждением того, что цель «оживления» Северо-Востока всё ещё далеко не достигнута, могут служить новые инициативы в этом направлении. Нынешняя администрация во главе с президентом Си Цзиньпином, подтверждая сохраняющуюся актуальность проблемы оживления северо-восточного региона, в августе 2014 г. и апреле 2016 г. анонсировала обновление планов решения связанных с этим задач. 
В совместном политическом документе ЦК КПК и Государственного совета «Некоторые мнения относительно всестороннего возрождения старых промышленных баз, включая северо-восток», появившемся в 2016 г., предложенная стратегия названа «основной политикой нового века», подчёркивая, что этот период будет иметь решающее значение для возрождения региона. Согласно документу, регион испытывает нарастающее давление на экономический рост, тогда как государственные предприятия по-прежнему остаются недостаточно жизнеспособными. К 2020 году, отмечается в нём, отрасли, переживающие спад, и регионы с истощающимися ресурсами должны кардинальным образом изменить свои модели роста [1].

Эти планы, как и раньше, нацелены на содействие «реформе и развитию частной экономики», включая такие меры, как сокращение пространства административных разрешений, открытие большего количества секторов для частных инвестиций, предоставление большей финансовой поддержки и государственно-частное партнёрство [12]. Отчасти повторяя стратегию возрождения северо-востока, взятую на вооружение центральным правительством в 2003 г., они также предусматривают множество вспомогательных мер, специально разработанных для региона. К концу 2017 г. центральным правительством было выпущено более 60 документов по этому вопросу, с созданием в рамках государственного аппарата значительной армии бюрократии, ориентированной на решение этой задачи [3]. И всё же все эти усилия центральных властей по оживлению «ржавого пояса» посредством оптимизации деловой среды, инвестиций в технологии или предложения стимулов для привлечения капиталов и молодых талантов, пока что окупаются не в полной мере. Традиционные отрасли промышленности, по-прежнему преобладающие в регионе, продолжают испытывать разного рода трудности, а утечка мозгов остается столь же острой проблемой. И в 2019 г. экономики Ляонина, Цзилиня и Хэйлунцзяна всё ещё находились среди тех, которые в наибольшей степени оказываются подверженными спаду [3].

Тем не менее, нельзя утверждать, что инициативы, связанные с усилиями по преодолению периферийности Северо-Востока, за прошедшие годы оказались безрезультатными. В то же время практические результаты этих попыток делают актуальными, как минимум несколько важных выводов. Во-первых, достигнутые позитивные изменения в развитии экономики и социальной сферы региона подтверждают значимость согласованной и всесторонней стратегии для управления региональным развитием, подобной той, которая была взята на вооружение центральными и местными органами власти Китая в 2003 г. вместо прежней разрозненной тактики решения отдельных вопросов. Во-вторых, даже такой подход, опирающийся на согласованные правительственные усилия в основном сверху вниз, не является гарантией успеха. Начавшаяся с 2003 г. «битва за будущее северо-востока, - констатирует в этой связи Э. Бэтсон, - стала косвенной дискуссией о выборе, стоящем 
перед Китаем, между рыночными реформами или государственной промышленной политикой» [14]. В рамках политики предоставления преференций Северо-Востоку правительство начало реализацию ряда программ, направленных на преодоление наиболее очевидных проблем, тормозящих развитие региона. Однако продолжающиеся государственные субсидии для государственных предприятий вступили в противоречие с обязательствами правительства по обеспечению развития частного рынка, а местные чиновники часто оказывались неспособными проводить рыночную политику. Наконец, ещё одним важным обстоятельством, ограничивающим эффективность предпринимаемых усилий, стало долго сохранявшееся упрощённое представление о возрождении старой промышленной базы, сводившее эту задачу к проблеме промышленных технологий без учёта важности системной реформы и институциональных инноваций. Таким образом, опыт прошедших лет ясно показывает, что успешное решение задачи оживления китайского «ржавого пояса» возможно только в рамках целостного регионального проекта, объединяющего экономический рост, социальный прогресс и улучшение экологии.

\section{Список литературы}

1. China to revitalize the Northeast. - URL: http://english.www.gov.cn/po licies/latest_releases/2016/04/27/content_281475336315607.htm (дата обращения: 29.09.2020).

2. Dong Lisheng. China's drive to revitalise the Northeast. - DOI https://doi.org/10.4000/chinaperspectives.462 // China Perspectives. - 2005. - № 58, March-April. - URL: http://journals.openedition.org/chinaperspectives/462 (дата обращения: 29.09.2020).

3. Disparities in China's regional growth: A look at H1 2019 GDP Data. China briefing. - URL: https://www.china-briefing.com/news/china-regional-growthdisparities-increased-h1-2019-gdp-growth-numbers/ (дата обращения: 29.09.2020).

4. Elaine Chan. China's Northeastern rust belt was once «Eldest Son», now struggling as runt of the litter. - URL: https://www.scmp.com/economy/chinaeconomy/article/3008778/chinas-northeastern-rust-belt-was-once-eldest-son-now (дата обращения: 29.09.2020).

5. EU-China cooperation activity on regional policy within the policy dialogue between DG REGIO and NDRC. Final report of Chinese expert. English language version // EU-China Cooperative Research Program on Regional Policy. Research Report of the Chinese Expert Group. December 2010. 375 p. - URL: https:/ec.europa.eu/regional_poli cy/en/information/publications/studies/2010/euchina-cooperative-research-program-onregional-policy-research-report-of-the-chinese-expert-group (дата обращения: 29.09.2020). 
6. Li Fangchao. Plan to revitalize Northeast region. - URL: https://www.chin adaily.com.cn/china/2007-08/09/content_6018172.htm (дата обращения: 29.09.2020).

7. Liu Shijin. Revitalizing the old industrial bases in Northeast ChinaCalls for new ways of thinking and strategic measures. - URL: http://en.drc.gov.cn/200312/01/content_36597899.htm (дата обращения: 29.09.2020).

8. Northeast China gets helping hand. - URL: http://en.people.cn/2 00311/27/eng20031127_129136.shtml (дата обращения: 29.09.2020).

9. Tan Khee Giap. 2014 Annual provincial and regional competitivenes analysis for greater China economies. Development strategies under the new normal / Tan Khee Giap, Yuan Randong, Sangiita Yoong Wei Cher. - Singapore : World Scientific Publishing Co. Pte. Ltd, 2015. - 356 p.

10. The economist intelligence unit. China's North-East: (Still) Striving for revitalisation. - URL: http://country.eiu.com/article.aspx?articleid $=1556388139 \&$ Co untry=China\&topic=Economy_1 (дата обращения: 29.09.2020).

11. The State Council Leading Group of revitalizing the old industrial bases in the Northeast region holds its first meeting // People's Daily. - 2004. - March 24.

12. Yuan Yang. Rust-Belt decline poses threat to Chinese. - URL: https://www.ft.com/content/ed8523ac-de36-11e7-a8a4-0a1e63a52f9c (дата обращения: 29.09.2020).

13. Zhang Pingyu. Revitalizing old industrial base of Northeast China: process, policy and challenge // Chinese Geographical Science. - 2008. - № 18 (2). - P. 109-118.

\section{References}

1. China to revitalize the Northeast. Available at: http://english.www.gov.cn/po licies/latest_releases/2016/04/27/content_281475336315607.htm (accessed 29 September 2020).

2. Dong Lisheng. China's drive to revitalise the Northeast. - DOI https://doi.org/10.4000/chinaperspectives.462. China Perspectives, 2005, no. 58, MarchApril. Available at: http://journals.openedition.org/chinaperspectives/462 (accessed 29 September 2020).

3. Disparities in China's regional growth: A look at H1 2019 GDP Data. China briefing. Available at: https://www.china-briefing.com/news/china-regional-growthdisparities-increased-h1-2019-gdp-growth-numbers/ (accessed 29 September 2020).

4. Elaine Chan. China's Northeastern rust belt was once «Eldest Son», now struggling as runt of the litter. Available at: https://www.scmp.com/economy/chinaeconomy/article/3008778/chinas-northeastern-rust-belt-was-once-eldest-son-now (accessed 29 September 2020).

5. EU-China cooperation activity on regional policy within the policy dialogue between DG REGIO and NDRC. Final report of Chinese expert. English language version. 
EU-China Cooperative Research Program on Regional Policy. Research Report of the Chinese Expert Group. December 2010. 375 p. Available at: https://ec.europa.eu/ regional_policy/en/information/publications/studies/2010/euchina-cooperative-researchprogram-on-regional-policy-research-report-of-the-chinese-expert-group (accessed 29 September 2020).

6. Li Fangchao. Plan to revitalize Northeast region. Available at: https://www.chi nadaily.com.cn/china/2007-08/09/content_6018172.htm (accessed 29 September 2020).

7. Liu Shijin. Revitalizing the old industrial bases in Northeast ChinaCalls for new ways of thinking and strategic measures. Available at: http://en.drc.gov.cn/200312/01/content_36597899.htm (accessed 29 September 2020).

8. Northeast China gets helping hand. Available at: http://en.people.cn/200311/27/ eng20031127_129136.shtml (accessed 29 September 2020).

9. Tan Khee Giap, Yuan Randong, Sangiita Yoong Wei Cher. 2014 Annual provincial and regional competitivenes analysis for greater China economies. Development strategies under the new normal. - Singapore: World Scientific Publishing Co. Pte. Ltd, 2015. $-356 \mathrm{p}$.

10. The economist intelligence unit. China's North-East: (Still) Striving for revitalisation. Available at: http://country.eiu.com/article.aspx?articleid=1556388139\& Country $=$ China\&topic=Economy_1 (accessed 29 September 2020).

11. The State Council Leading Group of revitalizing the old industrial bases in the Northeast region holds its first meeting. People's Daily, 2004, March 24.

12. Yuan Yang. Rust-Belt decline poses threat to Chinese. Available at: https://www.ft.com/content/ed8523ac-de36-11e7-a8a4-0a1e63a52f9c (accessed 29 September 2020).

13. Zhang Pingyu. Revitalizing old industrial base of Northeast China: process, policy and challenge. Chinese Geographical Science, 2008, no. 18 (2), pp. 109-118. 